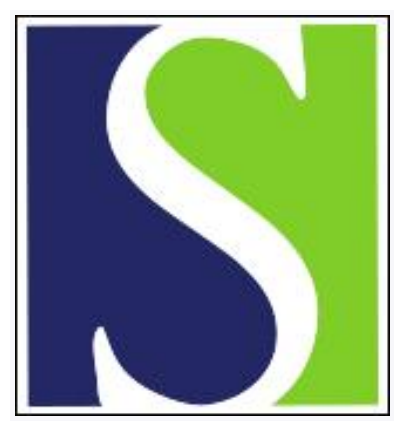

Scand J Work Environ Health 1978;4(1):47-53

https://doi.org/10.5271/sjweh.2758

Issue date: 1978

Radiologically detectable lumbar disc degeneration in concrete reinforcement workers.

by Wiikeri M, Nummi J, Riihimäki H, Wickström G

Key terms: back; back symptom; concrete reinforcement work; concrete reinforcement worker; disc degeneration; lumbar disc; lumbar disc degeneration; radiology; X-ray

This article in PubMed: www.ncbi.nlm.nih.gov/pubmed/663571

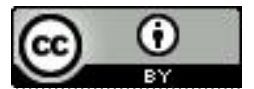




\title{
Radiologically detectable lumbar disc degeneration in concrete reinforcement workers
}

\author{
by MATTI WIIKERI, M.D.,1 JUHANI NUMMI, M.D., ${ }^{1}$ HILKKA RIIHIMÄKI, M.D., ${ }^{2}$ \\ and GUSTAV WICKSTRÖM, M.D. ${ }^{3}$
}

\begin{abstract}
WIIKERI, M., NUMMI, J., RIIHIMÄKI, H. and WICKSTRÖM, G. Radiologically detectable lumbar disc degeneration in concrete reinforcement workers. Scand. $j$. work environ. \& health 4 (1978): suppl. 1, 47-53. Two hundred and ninety-five male Finnish concrete reinforcement workers, aged 19 to 64 years and engaged in heavy physical work including prolonged stooping, were radiologically examined by antero-posterior and lateral views of the lumbar spine while they were standing. The findings of lumbar disc degeneration were classified as none, slight, moderate or severe. The prevalence and degree of radiologically detectable lumbar disc degeneration depended strongly on age and increased especially rapidly from 40 to 44 years on. Lumbar disc degeneration showed an age-independent association to both a history of lumbago $\left(\chi^{2}=10.5, p<0.01\right)$ and a history of sciatica $\left(\chi^{2}=11.8, \mathrm{p}<0.001\right)$. When disc degeneration was compared to reports of stiffness, fatigue, ache, and sharp pain in the back during an ordinary workday, no statistically significant associations were found, while disc degeneration was found to be slightly more common $\left(\chi^{2}=4.6, \mathrm{p}<0.05\right)$ in the men reporting back symptoms as they bent down than in the men who did not report such sympitoms. No association between length of exposure to static and dynamic back loads in reinforcement work and the prevalence of lumbar disc degeneration could be established, but definite conclusions on the possible effect of reinforcement work on the lumbar spine could not be drawn from the data.
\end{abstract}

Key words: back symptom, concrete reinforcement worker, lumbar disc degeneration, $\mathrm{X}$ ray.

In the general population the prevalence of radiologically detectable lumbar disc degeneration increases almost linearly between 25 and 50 years of age, after which the increase slows down. By the age of 65 years the prevalence is over $90 \%$ (7). Long-term stress plays an important role in the different forms of disc tissue changes (12). Heavy physical work, especially mining, accelerates the degenerative process $(1,2,4,5,8)$.

Concrete reinforcement workers are skilled construction workers. Their task is

1 Institute of Occupational Health, Helsinki, Finland.

2 Labor Pension Fund, Helsiniki, Finland.

3 Turku Regional Institute of Occupational Health, Turku, Finland. to build steel skeletons upon which concrete is later poured by other workers. Reinforcement work consists of pulling long steel rods from a stack, cutting and bending the rods (mostly by machines), and tying the rods together according to sketches. An ergonomic study of back loads in reinforcement work showed great static loads from working in bent-double and forward-leaning postures during the tying tasks. Dynamic loads occurred mainly in the preparation tasks and were considered of less importance than the static ones; even so, the substantial momentary load of lifting rods in a stooped posture when disengaging them from the stack and the dynamic load of pulling the rods to the cutting and bending machines were 
also regarded as loads which might contribute to a possible premature degeneration of the lumbar intervertebral discs (11).

To evaluate the effect of concrete reinforcement work on the back, we made a cross-sectional epidemiologic study of the backs of 295 male Finnish concrete reinforcement workers aged 19 to 64 years. Additional characteristics of the population studied and the experience of lowback pain syndromes and back symptoms in this group have been reported in an article by Wickström et al. (13).

In this article we have reported the prevalence of lumbar disc degeneration in reinforcement workers by age and have compared the length of reinforcement work to the prevalence of degenerative changes. We have also compared the radiological findings with the history of lowback pain syndromes and with present back symptoms.

\section{METHODS}

The reinforcement workers were radiologically examined by an antero-posterior and a lateral view of the lumbar spine; in the antero-posterior projection, the sacroiliac joints were included. The radiographs were taken with a Siemens Tridoros 4 apparatus on $20 \times 40 \mathrm{~cm}$ Agfa-Gaevert film. The subject was standing straight with the $\mathrm{X}$-ray tube at a distance of $1.5 \mathrm{~m}$ at the level of the crista ilica. Large focus was used. Exposure values, about $75 \mathrm{kV}$ and $100 \mathrm{mAs}$ in the antero-posterior projection and about $90 \mathrm{kV}$ and $200 \mathrm{mAs}$ in the lateral projection, were modified according to the body build of the subject examined. The sector of the X-nay beams was screened down to limit the exposure of tissues to radiation.

The radiological parameter determined in this study was lumbar disc degeneration. It was graded on four levels as "none," "slight," "moderate," or "severe" according to the following definitions:

none $=$ no signs of disc degeneration, slight $=$ narrowing of intervertebral space without other signs of disc degeneration, moderate $=$ narrowing of intervertebral space and osteophytosis, severe $=$ narrowing of intervertebral space, osteophytosis, and end-plate sclerosis.

The radiographs were interpreted separately by a radiologist and an orthopedic surgeon. Both physicians knew they were looking at films of concrete reinforcement workers, but they had no knowledge of the age of the worker nor of any anamnestic or clinical orthopedic data. If their interpretations differed as to whether disc degeneration was present or if their classifioations of observed disc degeneration differed by more than one degree, the radiologist reviewed the films to consider the "suggestions" of the orthopedic surgeon. The radiologist's decision during this second reading was recorded as the definite classification.

In the graphic presentation of the results the findings are smoothed by calculation of the prevalence estimates for 15-year moving age ranges.

\section{RESULTS}

Radiologically detectable lumbar disc degeneration was found in $44 \%$ of the reinforcement workers. Below the age of 25 years no case was found, while the prevalence of disc degeneration increased swiftly from this age on, with an especially sharp rise from age $40-44$ years to age $45-49$ years. In the age group $60-64$ years only one man did not show any signs of lumbar degeneration (table 1).

The degree of lumbar disc degeneration was classified as light in $12 \%$ of the men, as moderate in $23 \%$, and as severe in $9 \%$. The relation between degree of disc degeneration and age is shown in fig. 1 . The prevalence of moderate and severe changes increased rapidly from age 45 years on.

We analyzed the effect of reinforcement work on lumbar disc degeneration by comparing the length of experience in concrete reinforcement work to radiologically detectable signs of lumbar disc degeneration. For the age groups $35-39,40-44,45-49$ and $50-54$ years no statistically significant association was found with Mantel's test (9). 
Table 1. Radiologically detectable lumbar disc degeneration by the age of the subjects and their experience in reinforcement work.

\begin{tabular}{|c|c|c|c|c|c|c|c|c|c|c|c|}
\hline \multirow{2}{*}{$\begin{array}{l}\text { Experience } \\
\text { in reinforce- } \\
\text { ment work } \\
\text { (years) }\end{array}$} & \multicolumn{11}{|c|}{ Age group (years) } \\
\hline & $\begin{array}{l}15-19 \\
(\mathrm{~N}=1)\end{array}$ & $\begin{array}{c}20-24 \\
(N=14)\end{array}$ & $\begin{array}{c}25-29 \\
(\mathrm{~N}=32)\end{array}$ & $\begin{array}{c}30-34 \\
(N=46)\end{array}$ & $\begin{array}{c}35-39 \\
(\mathrm{~N}=52)\end{array}$ & $\begin{array}{c}40-44 \\
(N=57)\end{array}$ & $\begin{array}{c}45-49 \\
(\mathrm{~N}=35)\end{array}$ & $\begin{array}{c}50-54 \\
(\mathbf{N}=28)\end{array}$ & $\begin{array}{c}55-59 \\
(\mathbb{N}=20)\end{array}$ & $\begin{array}{c}60-64 \\
(\mathbb{N}=10)\end{array}$ & $\begin{array}{c}15-64 \\
(\mathrm{~N}=295)\end{array}$ \\
\hline $\begin{array}{c}0-4 \\
(\mathrm{~N}=33)\end{array}$ & 0 & 0 & 2 & 1 & 1 & 0 & 0 & 0 & 0 & 0 & 4 \\
\hline $\begin{array}{c}5-9 \\
(\mathrm{~N}=77)\end{array}$ & . & 0 & 3 & 8 & 6 & 5 & 3 & 1 & 0 & 0 & 26 \\
\hline $\begin{array}{l}10-14 \\
(\mathrm{~N}=74)\end{array}$ & - & . & 1 & 4 & 6 & 9 & 7 & 5 & 3 & 1 & 36 \\
\hline $\begin{array}{l}15-19 \\
(\mathrm{~N}=47)\end{array}$ & - & . & $\cdot$ & 0 & 2 & 2 & 7 & 5 & 1 & 1 & 18 \\
\hline $\begin{array}{l}20-24 \\
(\mathrm{~N}=41)\end{array}$ & $\cdot$ & - & . & . & 0 & 5 & 9 & 9 & 4 & 1 & 28 \\
\hline $\begin{array}{l}25-29 \\
(N=13)\end{array}$ & $\cdot$ & $\cdot$ & · & - & $\cdot$ & 0 & 1 & 2 & 4 & 2 & 9 \\
\hline $\begin{array}{l}30-34 \\
(\mathrm{~N}=5)\end{array}$ & - & - & - & - & $\cdot$ & $\cdot$ & 0 & 2 & 2 & 1 & 5 \\
\hline $\begin{array}{l}35-39 \\
(N=4)\end{array}$ & $\cdot$ & $\cdot$ & . & $\cdot$ & $\cdot$ & . & . & 0 & 1 & 2 & 3 \\
\hline $\begin{array}{l}40-44 \\
(N=1) \\
\end{array}$ & - & • & . & . & . & . & . & . & 0 & 1 & 1 \\
\hline $\begin{array}{c}0-44 \\
(\mathrm{~N}=295)\end{array}$ & 0 & 0 & 6 & 13 & 15 & 21 & 27 & 24 & 15 & 9 & 130 \\
\hline
\end{tabular}

Lumbar disc degeneration was more frequent in workers with a history of lumbago or sciatica than in workers not reporting previous low-back syndromes $\left(\chi^{2}=21.1, \mathrm{p}<0.001\right)$. A history of lumbago was only weakly associated with radiologically detectable disc degeneration $\left(\chi^{2}=4.9, \mathrm{p}<0.05\right)$, while a history of sciatica was clearly related to severe $\left(\chi^{2}=\right.$ $9.1, \mathrm{p}<0.01$ ), to moderate and severe $\left(\chi^{2}=14.4, p<0.001\right)$, and also to slight, moderate and severe $\left(\chi^{2}=20.8, \mathrm{p}<0.001\right)$ lumbar disc degeneration. The association between lumbar disc degeneration and a history of both lumbago and sciatica was similar to that of sciatica alone (table 2).

As the prevalences of both a history of previous low-back pain syndromes and radiologically detectable lumbar disc degeneration accumulate as the age of the subject progresses, an association between these variables is to be expected. Hence allowance was made for age in the analysis. The two parameters "lumbar disc degeneration" and "history of lumbago" were combined into one parameter with four classes (disc degeneration negative

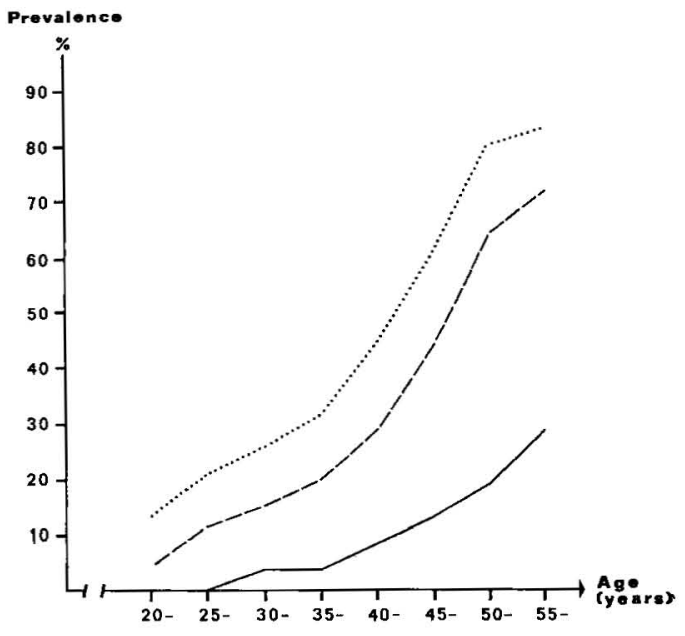

Fig. 1. Smoothed prevalence estimates of lumbar disc degeneration of different degrees by age. [Severe (-), moderate and severe $(--)$, slight, moderate and severe $(\ldots)$ changes]

and history of lumbago negative, disc degeneration positive and history of lumbago negative, disc degeneration negative and 
Table 2. Prevalence $(\%)$ of different degnees of lumbar disc degeneration in the subjects by experience of lumbago and/or sciatica.

\begin{tabular}{|c|c|c|c|c|}
\hline \multirow{3}{*}{$\begin{array}{l}\text { Prevalence } \\
\text { of lumbar disc } \\
\text { degeneration }\end{array}$} & \multicolumn{4}{|c|}{ History of low-back pain syndromes } \\
\hline & \multirow{2}{*}{$\begin{array}{c}\text { Neither } \\
\text { lumbago } \\
\text { nor } \\
\text { sciatica } \\
(\mathrm{N}=142)\end{array}$} & $\begin{array}{l}\text { Lumbago } \\
\text { but not } \\
\text { sciatica }\end{array}$ & $\begin{array}{l}\text { Sciatica } \\
\text { but not } \\
\text { lumbago }\end{array}$ & \multirow[t]{2}{*}{$\begin{array}{l}\text { Both } \\
\text { lumbago } \\
\text { and } \\
\text { sciatica } \\
(\mathrm{N}=67)\end{array}$} \\
\hline & & $(\mathrm{N}=29)$ & $(\mathrm{N}=57)$ & \\
\hline Slight & 8 & 17 & 12 & 16 \\
\hline Moderate & 17 & 31 & 28 & 27 \\
\hline Severe & 5 & 3 & 18 & 15 \\
\hline Total & 30 & 51 & 58 & 58 \\
\hline
\end{tabular}

history of lumbago positive, and disc degeneration positive and history of lumbago positive). This combined variable is shown by age in fig. 2 . When lumbar disc degeneration and experience of lumbago were compared after age stratification, an association indicating a relationship independent of age $\left(\chi^{2}=10.5, \mathrm{p}<0.01\right)$ was found between these variables.

A similar four-class variable was constructed from the variables of "disc degeneration" and "history of sciatica," as shown in fig. 3 . When the relation between lumbar disc degeneration and a history of sciatica was analyzed in 5-year age groups by the Mantel-Haenszel's test (9), there was an association independent of age $\left(\chi^{2}=11.8, \mathrm{p}<0.001\right)$.

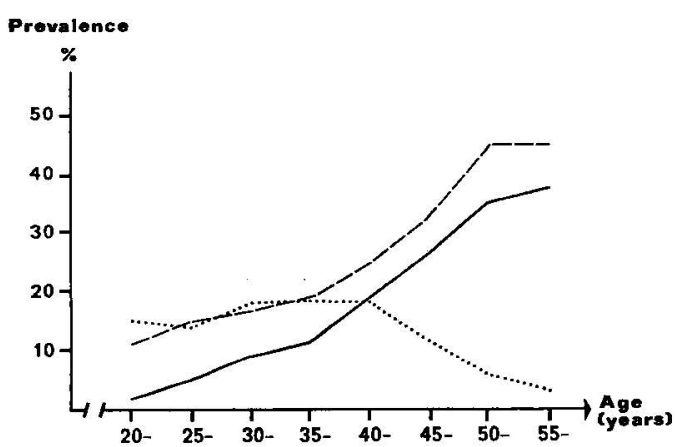

Fig. 2. Smoothed prevalence estimates of lumbar disc degeneration and/or history of lumbago by age. [Disc degeneration positive, history of lumbago positive (-); disc degeneration positive, history of Iumbago negative (- -$)$; disc degeneration negative, history of lumbago positive $(. .)$.
When lumbar disc degeneration was compared to present back symptoms, degenerative changes were slightly more common in the men reporting ache and sharp pain than in those without these symptoms. For fatigue and stiffness the radiological signs were somewhat more common among the symptom-free, but none of the differences were statistically significant (fig. 4).

Lumbar disc degeneration was more common in workers reporting back symptoms as they bent down than among the men without such symptoms $\left(\chi^{2}=4.6\right.$, $\mathrm{p}<0.05$ ), while symptoms in the stooped posture and during straightening up showed no relation to disc degeneration (fig. 5).

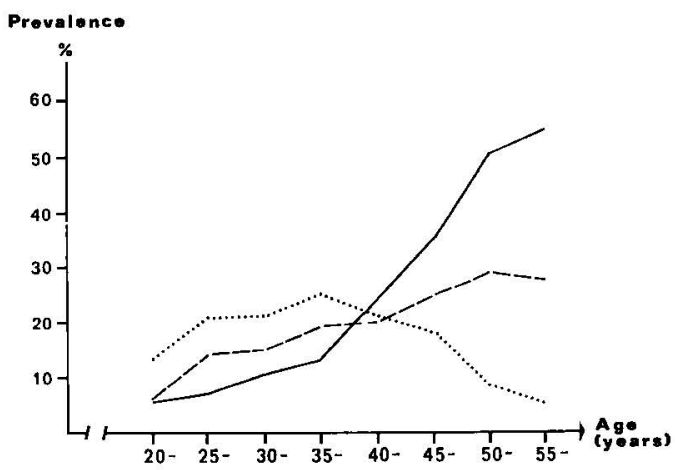

Fig. 3. Smoothed prevallence estimates of lumbar disc degeneration and/or history of sciatica by age. [Disc degeneration positive, history of sciatica positive $(-)$; disc degeneration positive, history of sciatica negative (- - ); disc degeneration negative, history of sciatica positive $(. .$.$) ]$ 


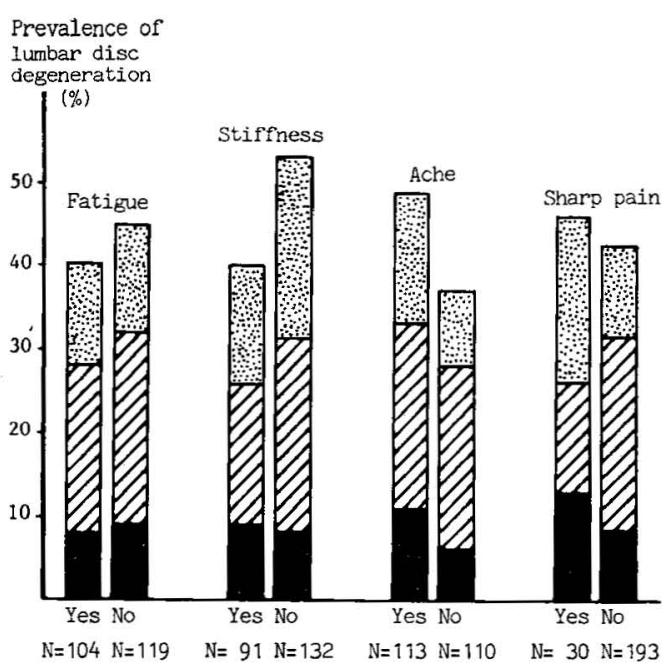

Fig. 4. Prevalence of lumbar disc degeneration in reinforcement workers with and without present back symptoms [Severe ( $\square$ ), moderate (ש), and slight (圈) disc degeneration]. The differences are not significant.

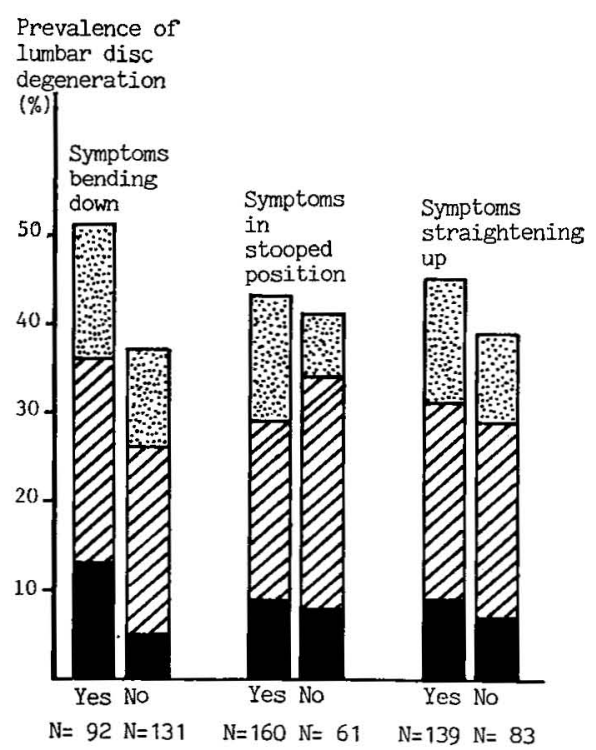

Fig. 5. Prevalence of lumbar disc degeneration in reinforcement workers with and without back symptoms during bending down, in a stooped posture, and during straightening up

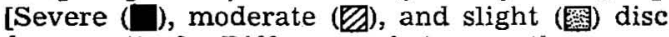
degeneration]. Difference between those reporting and those not reporting back symptoms at a certain phase of stooping was statistically significant only for symptoms during bending down; radiologically detectable lumber disc degeneration was more common in men reporting back symptoms during bending down than in those not reporting such symptoms $\left(\chi^{2}=\right.$ 4.6, $\mathrm{p}<0.05$ ).

\section{DISCUSSION}

Degeneration of the intervertebral discs is the first degenerative change in the lumbar spine. The observed prevalences of disc degeneration vary with the methods of investigation. Histological examination of the disc tissue is the most sensitive method, but also macroscopic autopsy studies yield higher prevalence figures than do radiological examinations of the lumbar spine in living subjects. Even relatively advanced disc degeneration may not be revealed by ordinary radiological methods (3).

The radiologically detectable signs of disc degeneration are diminished height of the intervertebral disc space, sclerosis of the adjacent vertebral plates, and growth of osteophytes.

The interobserver error in the evaluation of degenerative lumbar changes has been found to be great even among experienced interpreters; it mainly concerns differentiation between slight and moderate changes $(5,6)$. In our study the radiologist first classified the findings of lumbar disc degeneration as negative in 187 men, slight in 24 , moderate in 61 , and severe in 23 men. For the orthopedist the corresponding figures were 184, 40, 51 and 20 , respectively. The radiologist thus classified fewer findings as slight and more findings as moderate than the orthopedist. Otherwise no consistent difference was discerned. After the reevaluation of the differently classified radiographs, the radiologist revised his classification in 30 cases. Twenty-eight findings were classified as representing a higher degree of disc degeneration than on the first interpretation, while two findings were reclassified to a lower level.

The possible effect of reinforcement work on lumbar disc degeneration was found difficult to interpret from the results of the present cross-sectional study. The age of the workers was quite closely related to the length of their experience in reinforcement work and most reinforcement workers had been employed in other physically strenuous occupations before entering reinforcement work (13).

When the data were evaluated by Mantel's method (9), there was no statis- 
tically significant increase in the prevalence of degenerative changes because of occupational factors. No reference group was investigated explicitly to serve for comparison with the reinforcement workers. As the method for interpretation of radiologically detectable lumbar disc degeneration used in the present study is not identical to the methods employed in other studies made at the Institute of Occupational Health and as interobserver errors are known to be considerable, it is not possible to make a reliable comparison between the prevalence of lumbar disc degeneration in concrete reinforcement workers and other occupational groups already studied.

Clear evidence supporting the assumption that the occupational load on the back in concrete reinforcement work causes premature lumbar disc degeneration was not obtained in this study. Due to the design of the present investigation the results do not, however, rule out the possible existence of an occupational effect. The 5-year follow-up examination of the reinforcement workers and the simultaneous investigation of a reference group, both of which are being carried out at present, should help answer this question.

The relation between radiologically detectable lumbar disc degeneration and lowback pain syndromes has been investigated in several previous studies. Hult (4) emphasized that disc degeneration should be looked upon as a more or less physiological change coming with age. It need not give rise to symptoms, but it presumably lays the foundation for changes that cause back symptoms. Nachemson (10) considered that most of the low-back disorders ultimately turn out to be discogenic, though others disagree.

Lumbar disc degeneration, especially pronounced changes, has been found to be more common in persons with a history of back symptoms than in persons without, but comparison of disc degeneration to different types of back trouble (insufficiency symptoms, lumbago and sciatica) provided no additional information (4). When radiologically detectable lumbar disc degeneration is related to reported experience of back-hip sciatic pain, both sensitivity, $59 \%$, and specificity, $55 \%$, are low. However, the correlation rises when incapacitating rather than trivial pain is considered, past episodes rather than present manifestations, pronounced radiological changes rather than all degenerative signs, and young age groups rather than older ones $(7,14)$.

In the present study on concrete reinforcement workers slight, moderate, and severe lumbar disc degeneration was related to a history of sciatica, while only slight and moderate disc degeneration was more common in men with a history of lumbago alone as compared to men without a history of low-back pain syndromes. When the radiological findings of lumbar disc degeneration were compared to reports of present back symptoms, almost no association was found; only the relation to back symptoms during forward bending showed some statistical significance.

Radiological observations are of diagnostic value clinically, but they cannot show degenerative changes in the early stages. Nor do they demonstrate pain only a greater probability of pain for some of the observed changes. Radiological examination of the lumbar spine is an attractive method for evaluating low-back morphology in epidemiologic studies, as radiologically detectable signs of lumbar disc degeneration accumulate with age and exposure to physical loads. It may be looked upon as a biological "dosimeter," although defective, for occupational exposure to back loads. The primary drawbacks of the method are the health risks of the subjects from exposure to $\mathrm{X}$ rays and the heavy age dependence of the findings. Even in occupations which put substantial load on the back tissues of workers, a possible acceleration of the degenerative process in the lumbar spine is difficult to prove because the close relation between age and exposure often makes analysis difficult. A continuous selective process according to level of health leaves only the healthier in the group of active workers.

\section{REFERENCES}

1. BILLENKAMP, G. Körperliche Belastung und Spondylosis deformans. Fortschr. Röntgenstr. 116 (1972): 2, 211-216. 
2. CAPLAN, P. S., FREEMAN, L. M. and CONNELLY, T. P. Degenerative joint disease of the lumbar spine in coal miners A clinical and X-ray study. Arthritis rheum. 9 (1966): 5, 693-702.

3. HIRSCH, C. and SCHAJOWITZ, F. Studies on structural changes in the lumbar annulus fibrosus. Acta orthop. scand. 22 (1952) $184-231$.

4. HULT, L. Cervical, dorsal and lumbar spinal syndromes. Acta orthop. scand. suppl. 17 (1954) $102 \mathrm{p}$.

5. KELLGREN, J. H. and LAWRENCE, J. S. Rheumatism in miners: Part II. X-ray study. Br. j. ind. med. 9 (1952): 3, 197-207.

6. KELLGREN, J. H. and LAWRENCE, J. S. Radiological assessment of osteo-arthrosis. Ann. rheum. dis. 16 (1957) 494-502.

7. LAWRENCE, J. S. Disc degeneration: Its frequency and relationship to symptoms. Ann. rheum. dis. 28 (1969) 121-138.

8. LINNAM, A. T. Lumbo sacralis radiculitis in brimstone miners in Estonia (in Russian). Tarto State University, Tallin 1967. $30 \mathrm{p}$.
9. MANTEL, N. Chi-square tests with one degree of freedom; extensions of the Mantel-Haenszel procedure. J. am. stat. assoc. 58 (1963) $690-700$.

10. NACHEMSON, A. L. Low back pain: Its etiology and treatment. Clin. med. 1971 $18-23$.

11. SAARI, J. and WICKSTRÖM, G. Load on back in concrete reinforcement work. Scand. j. work environ. \& health 4 (1978): suppl. 1, 13-19.

12. SCHMORL, G. and JUNGHANNS, H. The human spine in health and disease (2nd Am. ed.). Grune \& Stratiton, New York, N.Y. 1971. 504 p.

13. WICKSTRÖM, G., HÄNNINEN, K., LEHTINEN, M. and RIIHIMÄKI, H. Previous back syndromes and present back symptoms in concrete reinforcement workers. Scand. j. work environ. \& health 4 (1978): suppl. 1, 20-28.

14. WOOD, P. H. N. Radiology in the diagnosis of arthritis and rheumatism. Trans. soc. occup. med. 22 (1972): 3, 69-72. 